\title{
Research on Evaluation of Information System Project based on Improved Binary Model
}

\author{
Chen Lina ${ }^{1,1}$ Zhao Wei ${ }^{3,1}$ \\ Information School \\ Capital University of Economics and Business \\ Beijing, China \\ e-mail:sarachen0209@126.com
}

\author{
Fan Jing ${ }^{2,2}$ \\ Labor economic school \\ Capital University of Economics and Business \\ Beijing, China \\ e-mail:atina1983@163.com
}

\begin{abstract}
Evaluating the actives during the project cycle especially when and where to invest is of vital importance. In this paper a series of ruled steps for evaluating the value information system are built. So that organization actives in the information system project can be evaluated and more available and appropriate choices can be made.
\end{abstract}

Keywords-binary tree; real option; information system project; informatization

\section{INTRODUCTION}

Information system project is a branch of $\mathrm{R} \& \mathrm{D}$ (research and development) project, it has many uncertainties in each stage of the project life cycle. Consequently, how to evaluate the project at the beginning of the project is of vital importance.

This paper aims to find a series of scientific steps to evaluate the value of the informatization project based on the theories of information system project management and real options method.

\section{TYPE STYLE AND FONTS}

The traditional methods to evaluate a project are Cash method and decision tree method. However, these methods are more paradox and the hypothesis are more ideal[1].Consequently, those methods can not take the real environment of the project into consideration, and the evaluations of the project are always lower than the real condition. Real options have the management flexible, so that it can reflect the investment options in each stage of the process of the projects, which much closer to the actual project construction environment.

Real option method is similar with the financial, but they are not exactly the same.

First of all, the stock call option is exclusive, and real options are often Shared with other competitors [2]. Second, the stock call option can be deal, but real option is generally cannot trade; Then, the value of the stock call option completely from the underlying assets stock, and real options is based on the option of options[3]; Finally, according to the characteristics of the information system project, the real option of $\mathrm{R} \& \mathrm{D}$ project is a multi-stage progress and follows discrete distribution.

The most widely used real option model mainly include: binary tree model, B $-\mathrm{S}$ model and Geske model. In this paper, we use binary tree model which can reflect the discrete progress of the informatization project to evaluation the real options

\section{IMPROVED BINARY TREE MODEL}

\section{A. binary tree model and informatization project}

R\&D project, especially the information system project, has long investment cycle, and because of that it has more risks, uncertainties [4-5]. The discrete real option are more appropriate to the characteristics of the project. Compared with B - S model and Geske model, binary tree model can be used with discrete distribution. In addition, the binary tree model has a wider range of practicability and more flexibility, and the hypothesis of the model does not need complex financial or mathematics knowledge [68].Consequently, the workload can be largely reduced.

Binary tree option model is founded by $\mathrm{J} \mathrm{C} \mathrm{Cox,} \mathrm{S} \mathrm{A}$ Ross and M Rubinstein。Assuming that the project initial value is $V_{0}$, the validity period of the option has multiple time interval based on asset volatility, each interval is $\Delta t$. The asset prices only have two kinds of acts: $\operatorname{profit}^{+}$or liquidation $V^{-}$

$$
\text { Set } V^{+}=V_{0} u, V^{-}=V_{0} d \text {, u and d means at the end of }
$$
this stage the value of the project are $u$ or $d$ times of the initial value of the project respectively. The risk neutral probability is $\mathrm{p}$, and the real options are $V^{+}$and $V^{-}$. In each stages of the project, cash follow is $C_{i}$.

Binary tree option pricing theory is based on the risk neutral method, and the expectations of tradable asset returns are risk-free return. In the time interval of $\Delta t$, the expectations value of the asset is:

$$
\begin{aligned}
& V_{0} e^{r \Delta t}=p V^{+}+(1-p) V^{-} \\
& V_{0} e^{r \Delta t}=p V_{0} u+(1-p) V_{0} d \\
& e^{r \Delta t}=p u+(1-p) d
\end{aligned} \quad(r \text { is risk-free interest rate })
$$

Asset price follows geometric Brownian motion, and in a small time, the variance of asset price changes is $s^{2} e^{2 r \Delta t}\left[e^{\sigma^{2} \Delta t}-1\right]$,
variance of is:
$\operatorname{Var}\left(V_{0}\right)=E\left(V_{0}^{2}\right)-\left[E\left(V_{0}\right)\right]^{2}$,

then: 


$$
\begin{aligned}
& V_{0}^{2} \sigma^{2} \Delta t=p V_{0}^{2} u^{2}+(1-p) V_{0}^{2} d^{2}-[p u+(1-p) d]^{2} V_{0}^{2} \\
& \sigma^{2} \Delta t=p u^{2}+(1-p) d^{2}-[p u+(1-p) d]^{2}
\end{aligned}
$$

Cox, Ross and Rubinstein set

$u=\frac{1}{d}$

According to (1), (2), (3):

$$
p=\frac{e^{r \Delta t}-d}{u-d} ; u=e^{\sigma \sqrt{\Delta t}} ; d=e^{-\sigma \sqrt{\Delta t}}
$$

The project value is :

$$
V_{0}=e^{-r \Delta t}\left[p V^{+}+(1-p) V^{-}\right]
$$

Because the project has cash follow in each stages, the initial real option of the project is:

$$
S_{0}=V_{0}-C_{1}
$$

In this paper, we improved binary tree model by the retake the parameter- risk neutral probability. In financial options, the risk neutral probability is got from $u=\frac{1}{d}$ [9]. However, the real options do not have the volatility and uncertainty of financial options。What's more, the value of the project real options do not follow the geometric

$$
\text { Brownian motion。Consequently, } u=\frac{1}{d} \text { is useless. }
$$

In the financial option, risk neutral probability $\mathrm{p}$ is the probability of options increases of the project in a time interval [10]. And in the construction of information system projects, in each stage of the project, there are two results, the project is successful, then go into the next phase of implementation; the project is fail, the do the capital liquidation. Therefore, we can use the project phase success probability q to replace risk neutral probability $\mathrm{p}$ in the calculation.

\section{B. Model parameters}

According to the information system project management theories, in the life cycle of the project, there 3 kinds of main risks: technology risk, team risk and environment risk [11-15].At each stage, the severity of each risk is different. Quantize all kinds of risks in each stages based in fuzzy comprehensive evaluation and expert scoring method, and then dimensionless the risks value, so that we can get the comprehensive risk value in different stages of the project value, namely the stage failure probability.

The process of defining project risk is as follows:

1) According to the milestone of the project implement, divide the project into several stages, and then define the different risks in different stages, build the risk structure matrix. Assuming that the project cycle has $\mathrm{m}$ stages.

2) Divide the risks into several level. The risks which can make the project fail regarded as the first level risk, weights a. The second one weights $b$, and so on. Set first level risk as the dimension.
3) Classify the risks in the project cycle and build the risk matrix. Assuming that different risks are independent.

Assuming that there were 3 kinds of risks in the project: technology risks, team risks and environment risks. The risks matrix are:

$$
\left(\begin{array}{ccc}
t_{11} & \ldots & t_{1 n} \\
\ldots & \ldots & \ldots \\
t_{m 1} & \ldots & t_{m n}
\end{array}\right),\left(\begin{array}{ccc}
r_{11} & \ldots & r_{1 n} \\
\ldots & \ldots & \ldots \\
r_{m 1} & \ldots & r_{m n}
\end{array}\right),\left(\begin{array}{ccc}
e_{11} & \ldots & e_{1 n} \\
\ldots & \ldots & \ldots \\
e_{m 1} & \ldots & e_{m n}
\end{array}\right)
$$

$t_{i j} 、 r_{i j}, e_{i j}$ are the i level risk technology risks, team risks and environment risks in the $\mathrm{j}$ stage of the project respectively.

4) Calculate the total risks in the different stages of the project cycle based on the risks matrix.

In stage 1 , technology risk is

$$
P_{T_{1}}=t_{11}+\frac{b}{a} t_{21}+\ldots+\frac{m}{a} t_{m 1}
$$

Team risk is

$$
P_{R_{1}}=r_{11}+\frac{b}{a} r_{21}+\ldots+\frac{m}{a} r_{m 1}
$$

Environment risk is

$$
P_{E_{1}}=e_{11}+\frac{b}{a} e_{21}+\ldots+\frac{m}{a} e_{m 1}
$$

5) Follow the steps in step 4, set one of the 3 risks as the dimension. Then build the overall risk matrix.

$$
\begin{aligned}
& \left(\begin{array}{ccc}
P_{T_{1}} & P_{T_{2}} & P_{T_{3}} \\
\phi_{1} P_{R_{1}} & \phi_{2} P_{R_{2}} & \phi_{3} P_{R_{3}} \\
\varphi_{1} P_{E_{1}} & \varphi_{2} P_{E_{2}} & \varphi_{3} P_{E_{3}}
\end{array}\right) \\
& P_{T_{i}}, P_{R_{i}}, P_{E_{i}} \text { means the probability of risk which can }
\end{aligned}
$$

lead to the failure of the project in the stage $\mathrm{i} ;{ }_{i}, \phi_{i}$ means environment risk and team risk weighting for the technology risk.

6)Calculate the total risk in different stage, namely the failure probability. And then gain the success probability.

$$
q_{i}=\left(1-P_{T_{i}}\right)\left(1-\phi_{i} P_{R_{i}}\right)\left(1-\varphi_{i} P_{E_{i}}\right)
$$

\section{Evaluate the project value with improved binary model}

To sum up, the step of how to evaluate the project value with improved binary model are as follows:

First, define the different risks in all the stages of the project, and build the risk matrix.

Second, Assuming that each risks are independent and demission all the risk to get the total risks matrix, then calculate the success probability in each stage.

Third, simulate assets change discrete process with improved multiple binary tree model.

Assuming that there were $\mathrm{n}$ stages in the project. At stage $V_{n-1}$, the value of the project is:

$$
V_{n-1}=\frac{p V_{n}^{+}+(1-p) V_{n}^{-}}{e^{r \Delta t}}
$$




$$
\begin{aligned}
& S_{n-1}=V_{n-1}-C_{n} \\
& V_{n-2}=\frac{p V_{n-1}^{+}+(1-p) V_{n-1}^{-}}{e^{r \Delta t}}
\end{aligned}
$$

From stage n, step by step, we can get the initial value of the project $V_{0}$ :

$$
V_{0}=\frac{p S_{1}+(1-p) V_{1}^{-}}{e^{r \Delta t}}
$$

Then,

$$
S_{0}=V_{0}-C_{1}
$$

Finally, compare the initial value with the expected results and determine whether to implement projects.

\section{Anlysis of numerical example}

In order to verify the research steps, we use a numerical example. The data of the example are taken from a manufacturing enterprise in Shanxi province, this enterprise planed to upgrade its management information system. As shown in table 1, the project can be divided into three stages according to the milestones, the periods are 1 year, 2 years, 3 years respectively. The main risk are technology risk, team risk and environment risk, Assuming those three risks in each stage are independent. Taking the risk-free interest rate $r$ is $5 \%$. If the value of the project is more than 5 million, the enterprise would do the investment.

TABLE I. DATA OF THE INFORMATIZATION PROJECT

\begin{tabular}{llll}
\hline Project & Stage I & Stage II & Stage III \\
\hline $\begin{array}{l}\text { Technology } \\
\text { Risk }\end{array}$ & 11 & 15 & 9 \\
Team & 8 & 6 & 7 \\
Risk & & & \\
Environment & 7 & 7 & 8 \\
Risk & & & \\
Team & 1.13 & 0.98 & 0.89 \\
Risk Weight & & & \\
Environment & 0.92 & 1.11 & 1.04 \\
Risk Weight & & & \\
Investment & 200 & 350 & 250 \\
& 180 & 300 & 350 \\
During Time & 1 & 2 & 1 \\
\hline
\end{tabular}

In the first, the success probability

is: $q_{i}=\left(1-P_{T_{1}}\right)\left(1-\phi_{i} P_{R_{1}}\right)\left(1-\varphi_{i} P_{E_{1}}\right)=75.74 \%$;

In the second stage, the success probability

is: $q_{2}=73.79 \%$;
In the third stage, the success probability is: $q_{3}=84.37 \%$.

Then, calculate the real option of the project with improved binary tree model.

$$
V_{n-1}=\frac{q_{i} V_{n}^{+}+\left(1-q_{i}\right) V_{n}^{-}}{e^{r \Delta t}}, \quad S_{n-1}=V_{n-1}-C_{n}
$$

The initial value of the project $V_{0}$ :

$$
V_{0}=\frac{q_{1} S_{1}+\left(1-q_{1}\right) V_{1}^{-}}{e^{r \Delta t}}, \quad S_{0}=V_{0}-C_{1}
$$

The calculation progress is shown in figure 1 .

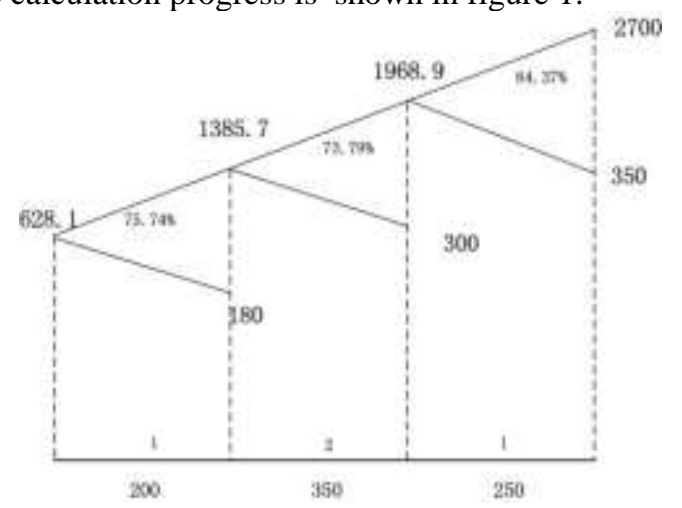

Figure 1. Project real options in each stage

Finally, we get the initial value of the project, which is 6.28 million, more than the expected project value. This enterprise should carry on the informatization project.

\section{CONCLUSION}

This paper has built a series of steps to evaluate the value of the information system project based on real option theory. Replace the neutral risk probability with the success probability of the informatization project which gains from the risks matrixes of the project cycle. Consequently, the improved model is more available and we can make some advise based on the model results.

However, there are still some problem for the real option method in practice. For example, we assume the risks in the project are independent, in real condition, this assumption is not alway availible.We still need to do more deeply research on the parameters of to improve the model.

\section{ACKNOWLEDGMENT}

This research was supported by the National Natural Science Foundation (No. 71240002), Beijing Philosophical Social Science Foundation (No. 11JGB077), Beijing Natural Science Foundation (No. 9123025).

\section{REFERENCES}

[1] Ma Mengmeng, Cai Chen, Wang Zhaoxiang. Research on enterprise R\&D project evaluation based on binary tree option model[J].China Management Science,2004, 12( 3) : 22- 27.

[2] Xia Jianming, Chen Yuanzhi. Real option theory review [J]. Journal of Shanghai financial institute, 2005(1): 4-13.

[3] Ma Xin, Wang Zhe. Real option theory in the investment project evaluation[J]. Management world, 2003(3): 140-141. 
[4] Ma Lina. Research on technology investment project evaluation theory and method[D]. Jilin university, 2007.

[5] Duan Shixia, Hu wenxiu, Jiang Hongbing. Evaluation of project investment based on real option[J]. Science and technology management research,2008(10): 136-138.

[6] Return On Information Technology Investment. Gothenburg University[D], 2004.

[7] Paul M. Tuten. A Model for the Evaluation of IS/IT Investments[D], Nova Southeastern University, 2009.

[8] MITTAL N, NAULT B R. Investments in Information Technology: Indirect Effects and Information Technology Intensity [J] . Information Systems Research, 2009, 20 (1): 140-154.

[9] J C Cox, S A Ross, M Rubinstein. Option Pricing: A Simplified Approach[J]. Journal of Financial Economics, 1979(10): 229-264.

[10] K T Yeo and Fashen Qiu. The value of management flexibility - a real option approach to investment evaluation[J]. International Journal of Project Management,2003,21: 243- 250.1.

[11] BENAROCH M, JEFFERY M, KAUFFMAN R J, SHAH S. Option - Based Risk Management: A Field Study of Sequential
Information Technology Investment Decisions[J]. Journal of Management Information Systems, 2007, 24(2) :103-140.

[12] DEWAN S, SHI C, GURBAXANI V. Investigating theRisk Return Relationship of Information Technology Investment: Firm - Level Empirical Analysis [J]. Management Science, 2007, 53 (12): 1829 1842 .

[13] BRYNJOLFSSON E. The Productivity Paradox of Information Technology: Review and Assessment [J]. Communication of ACM, 1993, (35): 66-77.

[14] WEILL P. The Relationship Between Investment in Information Technology and Firm Performance: A Study of the Valve Manufacturing Sector [J]. Information Systems Research, 1992,3(4): 307-333.

[15] THOUIN M F, HOFFMAN J J, FORD E W. The Effect of Information Technology (IT) Investments on Firm- Level Performance in the Healthcare Industry $[\mathrm{J}]$. Health Care Management Review, 2008, 33 (1): 60-69. 